\title{
Experimental Evaluation of Corrugated Feed Channel of Direct Contact Membrane Distillation
}

\author{
Mabrouk $A^{1 *}$, Elhenawy $Y^{2}$ and Moustafa $\mathbf{G}^{2}$ \\ ${ }^{1}$ Qatar Environment and Energy Research Institute, Hamad Bin Khalifa University, Qatar Foundation, Qatar \\ ${ }^{2}$ Port Said University, Egypt
}

\begin{abstract}
Membrane distillation is a hybrid process in which the separation process is based on both thermal potential and membrane characteristics. However, some technical challenges such as thermal boundary layer builds up (temperature polarization) resulted in low mass flux. In this study, the direct contact membrane distillation is equipped with corrugated feed channel to create fluid mix for mass flux improvement. A lab scale flat sheet membrane distillation is assembled with corrugated feed channel to suppress the thermal boundary layer in the vicinity of the membrane wall. The flat sheet PTFE- membrane of a pore size of $0.45 \mu \mathrm{m}$ and porosity $65 \%$ is considered in the present study. The effect of feed channel gap height has been investigated at different values of flow rate, feed temperature, and feed salinity.

The experiments showed that the corrugated feed channel has a dominant effect of improving of the mass flux and the thermal efficiency rather than gap height and operating conditions. The experimental results showed the water flux and thermal efficiency of the corrugated feed channel module is $44 \%$ and $33 \%$ higher than the original module respectively.
\end{abstract}

Keywords: Membrane distillation; Heat transfer; Corrugated surface; Gap; Desalination

\section{Nomenclature}

A: Membrane area, $\mathrm{m}^{2}$

Cp: Specific heat capacity of fluid $\left(\mathrm{J} \mathrm{kg}^{-1} \mathrm{~K}^{-1}\right)$

LHv: Latent heat of vaporization of water $\left(\mathrm{J} \mathrm{kg}^{-1}\right)$

$\mathrm{Nm}$ : Water flux $\left(\mathrm{kg} \mathrm{m}^{-2} \mathrm{~s}^{-1}\right)$

EE: Energy efficiency (\%)

T: Temperature $\left({ }^{\circ} \mathrm{C}\right)$

$\mathrm{m}$ : Mass flow rate $(\mathrm{kg} / \mathrm{sec}$.

Subscripts

f: Feed

fi, fo: Entrance, outlet of feed

m: Membrane, or membrane surface

p: Permeate

pi, po: Entrance, outlet of permeate

pm: On permeate-side membrane surface

\section{Introduction}

Membrane distillation (MD) is a thermally based separation process in which hydrophobic membrane assist phase change to let only vapor pass through membrane wall. This process may be used not only for desalination of seawater and brackish water but also concentration valuable substances. Membrane distillation differs than RO in the way of separation mechanism and the dominant driving force. On the other hand, earlier work [1] of describing the separation process considered membrane distillation is an infinite stage flash evaporation since each pore acts as a separate stage [1]. The MD has a unique characteristic rather than the mature technology Reverse Osmosis (RO) since it works at a low pressure feed. The MD also has advantage rather than the conventional distillation methods such as Multi-Stage Flash (MSF) and Multi Effect distillation (MED) such that it utilizes low-grade heat and has no corrosion problems.

In addition, the MD can implement different non-volatile solutes under a wide range of concentration with a separation factor of $99.9 \%$. The separation factors depend on the solution, membrane and operating conditions [2-4]. However, using MD modules (flat sheet, spiral wound, hollow fibers) in industrial large scale application is a particular challenge due to the lack of uniform flow conditions, high pressure drop, and low packing density within module and lack of energy recovery.

The Temperature/concentration polarization is also considered a technical challenge which affecting the fluxes of the MD process [2,58]. From the process level prospective, increasing feed temperature would increase the mass flux however scale formation and deposit on the membrane surface would restrict the MD performance. Creating turbulence by pumping high feed flow rate in the feed channel showed an adequate increasing in the mass flux, however, specific pumping energy will become a particular concern.

Using lab scale direct contact $\mathrm{MD}(10 \mathrm{~cm} \times 25 \mathrm{~cm})$ cell, experimental evaluation has been conducted to investigate the effect of the feed flow hydrodynamics on the temperature polarization in PVDF $(0.2 \mu \mathrm{m}$ as mean pore size, $192 \mu \mathrm{m}$ as thickness, $48 \%$ overall porosity, and feed

*Corresponding author: Abdel Nasser Mabrouk, Scientist, Desalination and Water Reuse, Qatar Environment and Energy Research Institute, Qatar, Tel: 0097466966307; E-mail: aaboukhlewa@qf.org.qa

Received April 03, 2016; Accepted May 09, 2016; Published May 16, 2016

Citation: Mabrouk A, Elhenawy Y, Moustafa G (2016) Experimental Evaluation of Corrugated Feed Channel of Direct Contact Membrane Distillation. J Membra Sci Technol 6: 151. doi:10.4172/2155-9589.1000151

Copyright: (c) 2016 Mabrouk A, et al. This is an open-access article distributed under the terms of the Creative Commons Attribution License, which permits unrestricted use, distribution, and reproduction in any medium, provided the original author and source are credited. 
channel height of $1.3 \mathrm{~cm}$ ) [6]. As the Reynolds number increases higher than 2000, the temperature polarization coefficient increases higher than the value of 0.84 , which enhances the process performance [6].

Experimental study of applying a vacuum pressure on the feed and permeate channel of DCMD has been investigated [9]. This approach increased mass transport of water due to higher permeability and due to a total pressure gradient within the membrane [9]. The vacuum pressure is controlled in each MD channel by throttling valve at the channel entrance. However, some doubt about throttling process irreversibility and its effect on decreasing the temperature due to throttling.

Membrane distillation crystallization process has been tested [10]. This study showed that the MD can operate at a high concentration at feed temperature of 50 and $60^{\circ} \mathrm{C}$ with fluxes up to $20 \mathrm{LMH}$. Operating in batch concentration, the flux gradually declined due to the vapor pressure suppression and the concentration polarization existence. The experiments showed that the membrane wall temperature is about $5-10^{\circ} \mathrm{C}$ lower than the bulk temperature due to the existence of the temperature polarization which hinder the salt saturation and scale deposition formation [10].

A novel composite membrane distillation was prepared by blending the hydrophilic polysulfone with hydrophobic surface [11]. The hydrophobic surface is indirect contact to the hot feed solution however, the hydrophilic surface is in direct to permeate channel. The hydrophilic polymer concentration in blend is optimized to get a permeate flux of $43 \%$ higher than that the commercial PTFE membrane with $99.9 \% \mathrm{NaCl}$ salt rejection [11].

The effect of the thermal and the concentration boundary layers in aqueous lithium bromide solution is experimentally investigated using commercial PTFE membrane $(0.2 \mu \mathrm{m}$ as mean pore size, $80 \mu \mathrm{m}$ as thickness, $75 \%$ overall porosity) [7]. The results showed that the concentration boundary layer can be neglected only when concentration less than $5 \mathrm{wt} \%(50,000 \mathrm{ppm})$. However, the thickness of the thermal boundary layer was found larger than the concentration boundary layer which has prominent effect in the whole concentration range.

The integrated a small unit of direct contact membrane distillation equipped with a solar absorber is designed and investigated [12]. The absorber inserted between glass and the membrane to assist and to compensate the energy loss in the feed channel due to evaporation within membrane. The device performance is compromised under wide range of the hot stream temperature $\left(30-50^{\circ} \mathrm{C}\right)$ while absorb solar energy. The maximum trans-membrane flux is $4.1 \mathrm{~kg} /\left(\mathrm{m}^{2} \mathrm{~h}\right)$ with high purity which is $16.6 \%$ higher than that of the traditional membrane distillation operating under the same operating conditions without solar assist. However, the additional capital cost and complexity of solar absorber need to be evaluated.

For the same non-woven support layer, the PTFE membrane is superior to PVDF membrane and the scrim support layer is superior to the non-woven support layer based membrane [13]. This work highlighted that the support layer structure has significant effect rather than pore size on the membrane performance. The results shows for the thinner support and active layer, the mass flux is obtained as 46 $\mathrm{LMH}$ at $80^{\circ} \mathrm{C}$ which is comparable with that of the RO. However, long term operation in order to check fouling of scale deposit and wettability needs to be evaluated.

The process performance of different DCMD membranes with and without backing structure is experimentally and theoretically investigated [14]. The backing material reduces both mass flux and thermal efficiency significantly due to the impact of the effective diffusion path length and the complex thermal resistance. The thicker membrane reduces the flux with no influence on the thermal efficiency while the backing orientation towards the condenser side is advantageous [14].

An experimental evaluation to measure the effect of a spacer in the feed channels of the membrane is carried out [15]. The results showed that the fluxes can be enhanced by improving the mass transfer coefficient in terms of higher porosity-tortuosity factor. However in case of a poor convection heat transfer in liquid the spacers create turbulence and improve the mass transfer [15]. The effect of spacers (hydrodynamic angles range of $70-90^{\circ}$ and void of $60-70 \%$ ) on the mass flux for DCMD is experimentally investigated [8]. The channel filled spacer enhances the mass flux by $31-41 \%$ as a result of the created turbulence and the eddy flow in the vicinity of the membrane wall. This turbulence flow enhances the temperature polarization coefficient which reached to the unity [8].

Corrugated PVDF membrane was fabricated for improving flux stabilization in membrane distillation [16]. The corrugated composite flat sheet membrane showed much higher flux stability. The corrugated membrane operated with a minimal flux reduction and significantly less foulant accumulation and less salt deposition which attributed to the improved flow dynamics at the membrane surface and increased membrane surface induced bu surface corrugation.

The main objective of this study is to evaluate a new corrugated feed channel equipped with direct contact membrane distillation module. The aim of implementing a corrugated feed channel is to improve the flow and the hydrodynamic conditions in the vicinity of the membrane surface. A lab scale setup is assembled in order to conduct and to test the new module under different feed channel gap, different flow rate, and different feed temperature. For the sake of fair comparison, the new module is tested under the same operating condition of a traditional configuration.

\section{Experimental Set up Description}

A lab scale flat sheet membrane of $30 \mathrm{~cm} \times 30 \mathrm{~cm}$ dimensions with effective membrane area of $28 \mathrm{~cm} \times 28 \mathrm{~cm}$ is considered in the present experiments. The laminated PTFE membrane has a pore size, porosity and thickness of $0.45 \mu \mathrm{m}, 0.65$ and $127 \mu \mathrm{m}$, respectively. As shown in Figures 1 and 2, the hot streams are represented by red color while the permeate streams are represented by blue color. The hot water pump (Figure 2(2)) is circulating the hot fluid between electrical heater (Figure 2(1)) and the membrane module (Figure 2(6)). The hot fluid is directed to the membrane module through top port opening. The hot feed temperature decreases in the feed channel due to the loss of associated energy to the vapor permeate through the membrane. The electrical heater (Figure 2(1)) is compensating the temperature loss and increase the hot stream temperature to its initial temperature. The feed temperature varies between $42-68^{\circ} \mathrm{C}$. The cold water pump (Figure $2(8)$ ) is circulating the cold water between the chiller (Figure 2(7)) and the membrane module (Figure 2(6)). The temperature of the chilled water get increase through the permeate channel due to condensate of the vapor permeate. The chiller role is to restore the chilled stream to its initial permeate temperature. The chiller is used to control the permeate temperature in the range $20-30^{\circ} \mathrm{C}$. Flow rates of the feed and permeate are measured using rotameter. The temperature and the pressure are measured using thermocouple of type $\mathrm{T}$ and pressure transducers, respectively. The mass flux is determined by the weight of 


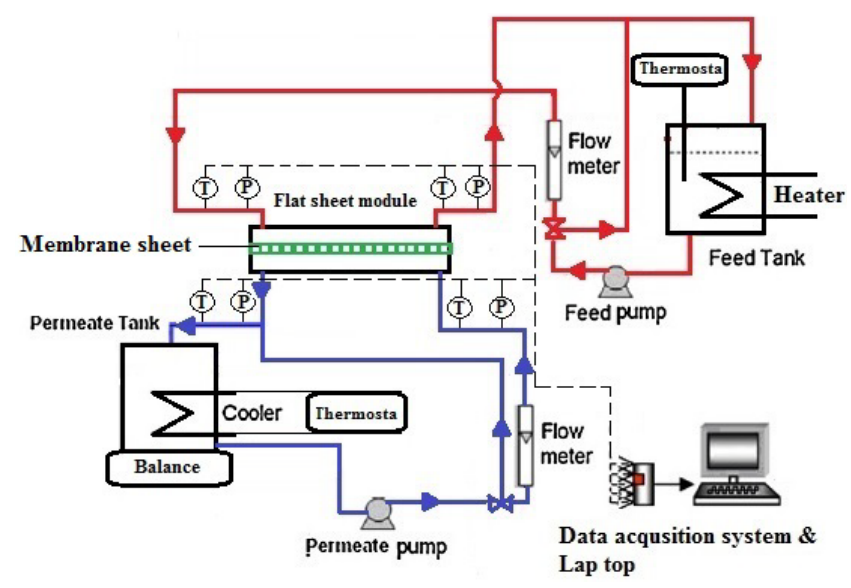

Figure 1: Flow diagram of DCMD module.

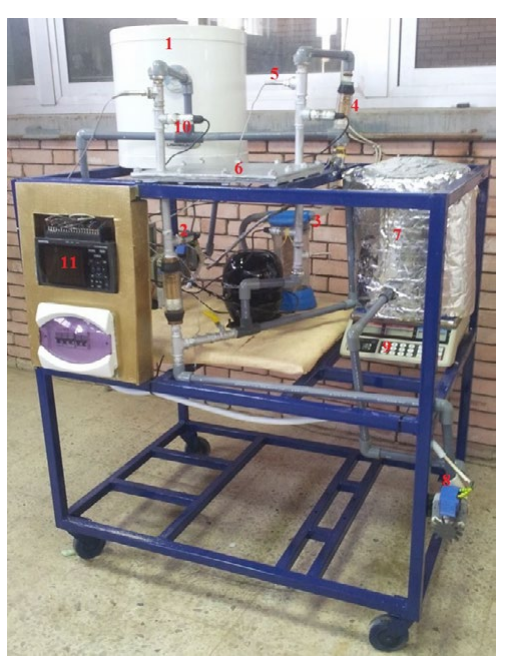

Figure 2: Experimental set up of DCMD unit.

1. Feed tank (with heater) 2. Feed pump 3. Filter 4. Rotameter 5 Thermocouple 6. DCMD module 7. Permeate tank (with chiller) 8

Permeate pump 9. Electronic balance 10. Pressure transducer 11. DAQ system

the distillate using weighing balance. Brine and permeate concentration are measured by TDS meter model. The data is recorded using DATAQ Instruments (Graphtec Model: GL220_820APS, Graphtec). In order to investigate the effect of feed salinity, $\mathrm{NaCl}$ with $45 \mathrm{~g} / \mathrm{l}$ is used as a feed solution. The hot feed flow rate varies between $30 \mathrm{l} / \mathrm{min}$ (Reynolds no. $=15.7)$ to $180 \mathrm{l} / \mathrm{h}($ Reynolds no. $=94)$ which indicates that the flow regime in the feed channel is laminar. While the permeate flow rate varies between $30-120 \mathrm{l} / \mathrm{h}$ which indicates that the flow regime in the permeate channel is also laminar.

Figure $3 \mathrm{a}$ shows the $3 \mathrm{D}$ drawing of the main parts of the corrugated feed channel DCMD module. The bottom plate, rubber, membrane sheet, spacer and top plates are assembled together using 12 pieces of Allen screw bolt and nuts. The overall size of each plate is $350 \times 350$ $\times 6 \mathrm{~mm}$. Figure $3 \mathrm{~b}$ shows the upper corrugated plate where slots are created. The width of each slot is $10 \mathrm{~mm}$ and depth is $3 \mathrm{~mm}$. Figure $3 \mathrm{c}$ shows the lower plate which is kept flat without corrugation. Each plate has holes which are machined to assemble both plate with membrane sheet in between using bolts and nuts. The spacer is equipped in between the top plate and the membrane sheet with a rubber gasket frame. Similarly, the rubber gasket thickness creates the permeate channel height between the bottom plate and the membrane sheet. The module was a rectangular thin channel with a hydraulic diameter of $5.93 \mathrm{~mm}$ that define the height of the flow channel of $3 \mathrm{~mm}$. This means that the corrugated feed channel would increase the Reynolds number by approximately two times of the traditional module. The rubber gasket of $1.5 \mathrm{~mm}$ is also used in the experiment to create gap of 1.5 $\mathrm{mm}$ height. The spacer foil thickness is $0.8 \mathrm{~mm}$. Using different rubber gasket thickness enables to create different gap heights. Similarly, the rubber frame inserted and fixed between the lower plate and the other face of the membrane sheet to create the permeate channel. For the sake of comparison under the same operating conditions, the corrugated module would be compared with traditional module. In order to show the effect of corrugation surface design and quantify its significant comparable to the traditional module under different feed flow rates, and different feed temperatures, the experimental test starts by using low feed salinity (450 ppm) to avoid the effect of fouling effect. Then after, the experimental work is conducted under high feed salinity of $45000 \mathrm{ppm}$.

The efficiency of the MD system is calculated by using equation 1 . The bulk temperature of the feed is used for calculating the latent heat of evaporation. The thermal efficiency of MD unit is given by [3]:

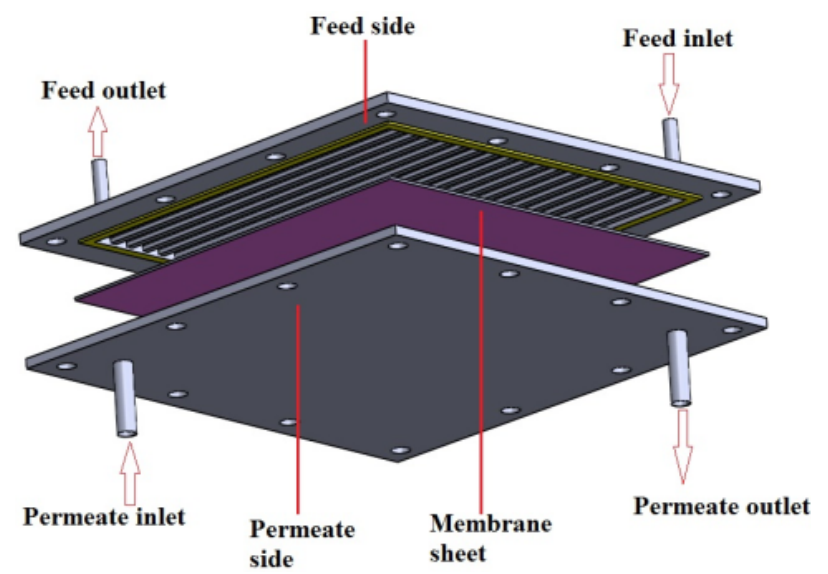

Figure 3a: Components of MD module with a membrane sheet.

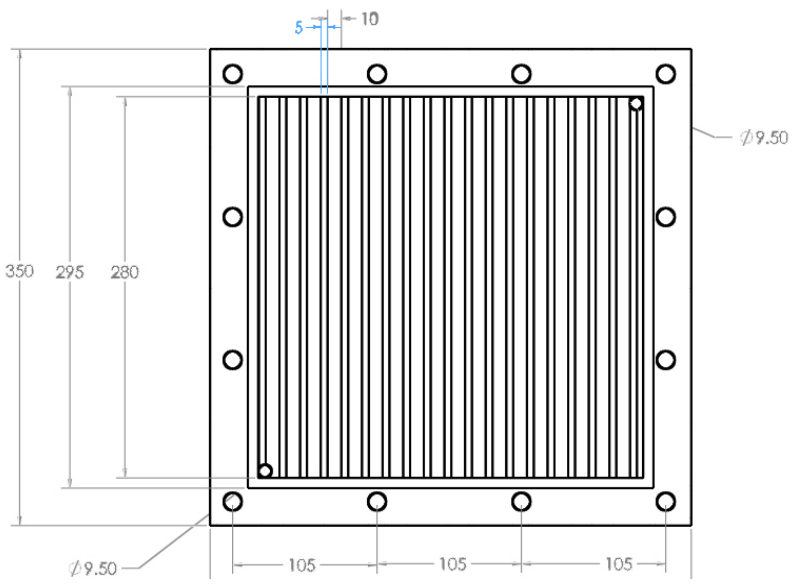

Figure 3b: Dimensions of the corrugated plate. 


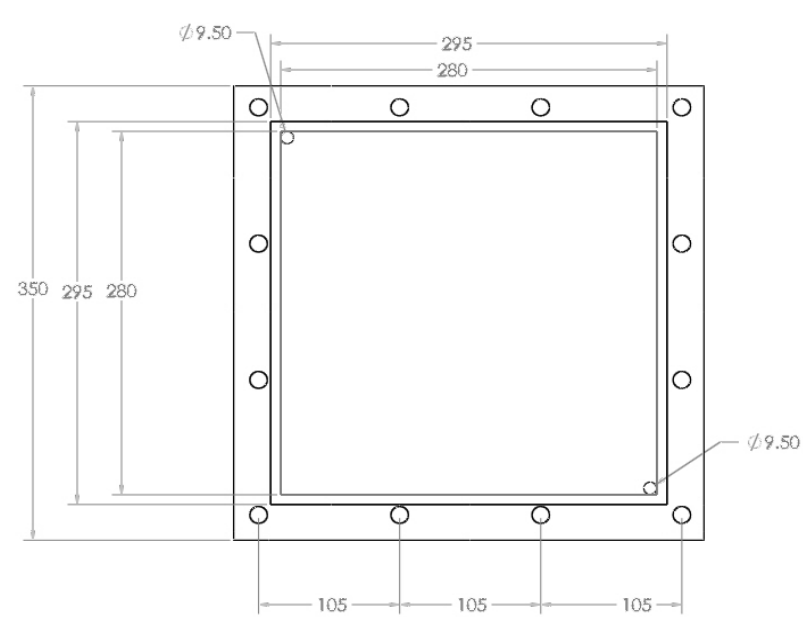

Figure 3c: Dimensions of the bottom plate.

$$
E_{E}=\frac{N_{m} A L H_{v}}{m_{p} C P_{p}\left(t_{p o}-t_{p i}\right)}
$$

Where, $\mathrm{A}$ is the effective membrane area, $m_{p}$ is the mass flow rate of the permeate, $N_{m}$ is the water flux, $L H_{v}$ is the latent heat of evaporation of water at the average temperature and $C P_{p}$ is the heat capacity of water at the average temperature.

$\mathrm{LH}_{v}$ can be calculated as follow [6]:

$$
L H_{v}(T)=1850.72 .8273 \mathrm{~T} 1.610^{-3} \mathrm{~T}^{2}
$$

The mass flux is calculated as:

$$
N_{m}=\frac{\Delta W}{A \times t}
$$

Where, $\Delta \mathrm{W}$ the difference in weight of permeate tank $(\mathrm{kg}), t$ is the time (h)

\section{Results and Discussion}

\section{Effect of the feed corrugated channel on the mass flux}

The feed flow rate and feed temperature are an important operating parameter due to its effect on the water flux, thermal efficiency and the temperature polarization. The effect of both feed flow rate and feed temperature on the mass flux is illustrated in Figures 4 and 5.

Figure 4 shows the mass flux variation at different feed temperature variation. The feed flow rate is fixed at $0.5 \mathrm{l} / \mathrm{min}$ and the permeate is fixed at $1 \mathrm{l} / \mathrm{m}$. The mass flux increases by decreasing the gap height. The experimental measurements show that at gap $=3 \mathrm{~mm}$, the average water flux of the corrugated module of DCMD is $32 \%$ higher than that of the original module, while the gap decreased to $1.5 \mathrm{~mm}$, the average water flux is $37 \%$ higher than that of the original module.

Figure 5 shows the effect of feed temperature and gap variation on the water flux while the feed flow rates fixed at $3 \mathrm{~L} / \mathrm{min}$. The experimental results show that at gap $=3$, the mass flux of the corrugated module is $34 \%$ higher than that of the original module. However, at gap of 1.5 $\mathrm{mm}$, the corrugated module enhanced the average water flux by $42 \%$ when it is compared with original module.

Figures 6 and 7 show the water fluxes for various permeate temperatures. The Feed solution was kept constant at $31 / \mathrm{min}$ and feed salinity at TDS $=0.45 \mathrm{~g} / \mathrm{l}$. The permeate temperature varies from 20 to $31^{\circ} \mathrm{C}$ however, for feed solution temperature side is kept constant at $68^{\circ} \mathrm{C}$.

Figure 6 shows that the water flux increases when permeate temperature is decreased. The corrugated module enhanced in the average water flux of DCMD by $35 \%$ at $3 \mathrm{~mm}$ gap. This enhancement occurs at permeate flow rate of $2 \mathrm{~L} / \mathrm{min}$.

Figure 7 shows the significant effect of the corrugated feed channel on the mass flux. The measured data shows that the corrugated module leads to an average water flux of DCMD by $44 \%$ at gap $=1.5 \mathrm{~mm}$ higher than that of the original module. This occurs at the permeate flow rate is $2 \mathrm{~L} / \mathrm{min}$. The permeate temperature varies from 20 to $31^{\circ} \mathrm{C}$ while the feed temperature is kept constant at $68^{\circ} \mathrm{C}$ and the feed flow rate is controlled at $3 \mathrm{~L} / \mathrm{min}$.

Table 1 shows the summary of the experimental results of the membrane distillation mass flux as a results of varying the gap height, the feed flow rate and the permeate flow rate. The percentage

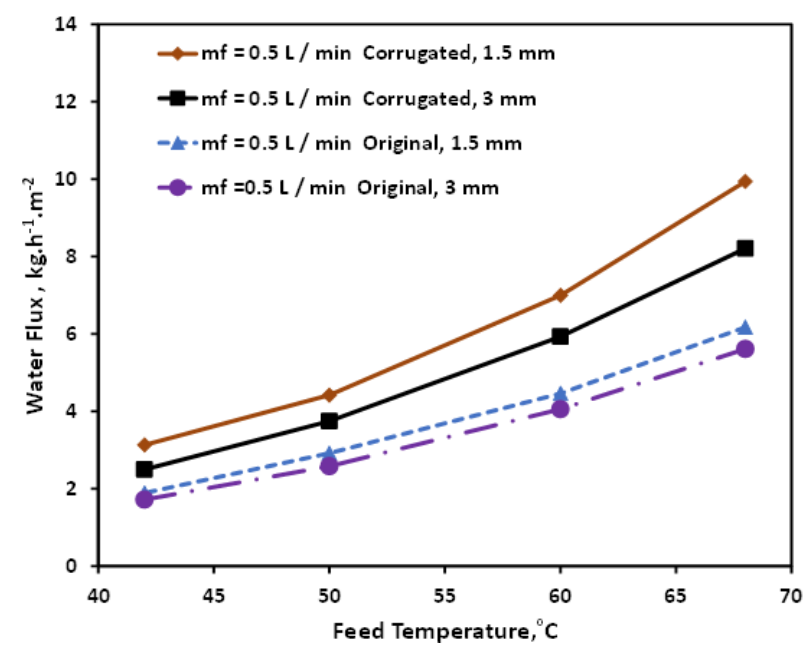

Figure 4: Water flux variation and gaps $(\mathrm{mf}=0.5 \mathrm{~L} / \mathrm{min}, \mathrm{mp}=1 \mathrm{I} / \mathrm{min}, \mathrm{tp}=$ $20^{\circ} \mathrm{C}$, TDS $=0.45 \mathrm{~g} / \mathrm{L}$ ).

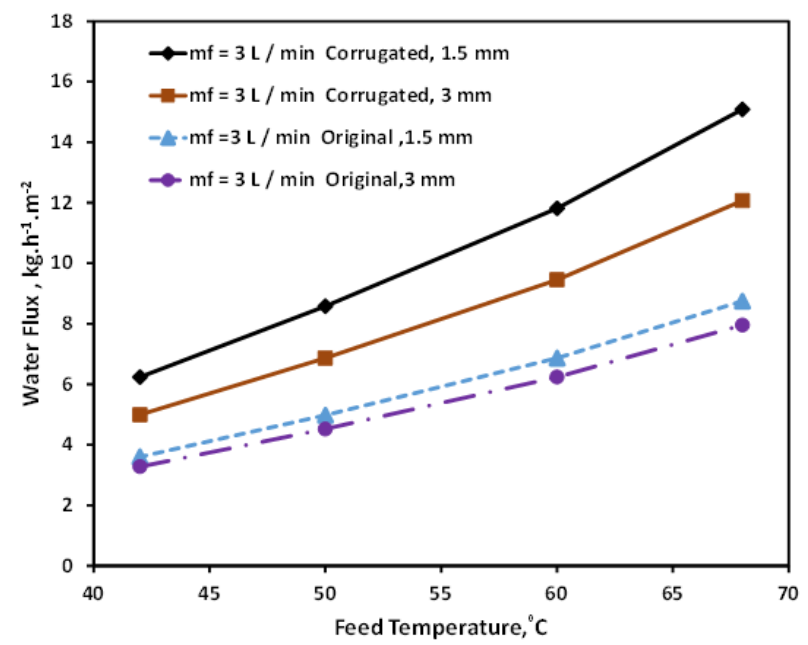

Figure 5: Water flux variation $\left(\mathrm{mf}=3 \mathrm{~L} / \mathrm{min}, \mathrm{mp}=1 \mathrm{~L} / \mathrm{min}, \mathrm{tp}=20^{\circ} \mathrm{C}\right.$, TDS $=0.45 \mathrm{~g} / \mathrm{L})$. 


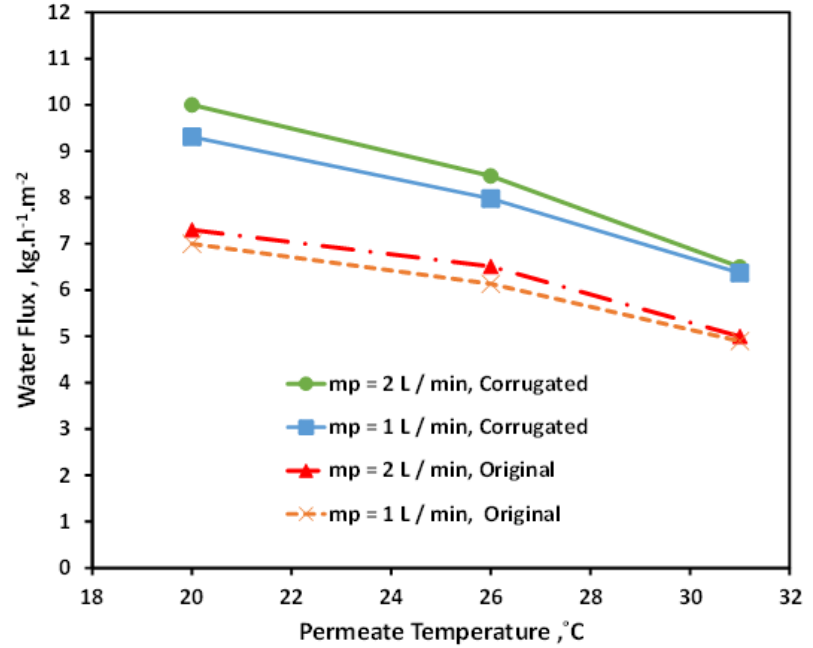

Figure 6: Effect of different permeate flow rate and temperature at gap $=3$ $\mathrm{mm}$ on water flux $\left(\mathrm{mf}=3 \mathrm{~L} / \mathrm{min}, \mathrm{tf}=68^{\circ} \mathrm{C}\right.$, TDS $\left.=0.45 \mathrm{~g} / \mathrm{L}\right)$.

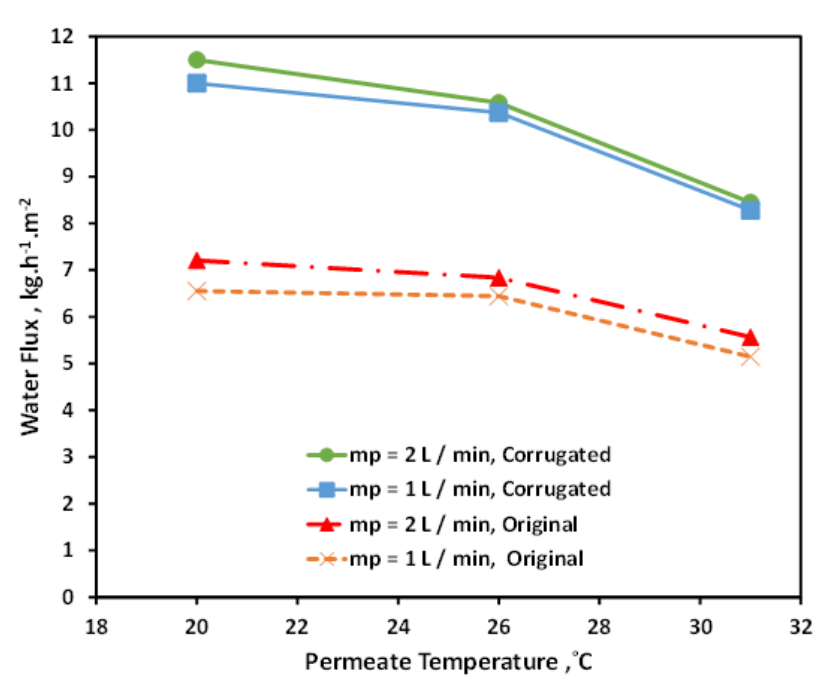

Figure 7: Effect of different permeate flow rate and temperature at gap $=1.5$ $\mathrm{mm}$ on water flux $\left(\mathrm{mf}=3 \mathrm{l} / \mathrm{min}, \mathrm{tf}=68^{\circ} \mathrm{C}\right.$, TDS $\left.=0.45 \mathrm{~g} / \mathrm{L}\right)$.

\begin{tabular}{|c|c|c|c|}
\hline $\begin{array}{c}\text { Feed flow rate, } \\
\text { L/min }\end{array}$ & $\begin{array}{c}\text { Gap height, } \\
\mathbf{3} \mathbf{~ m m}\end{array}$ & $\begin{array}{c}\text { Gap height } \mathbf{1 . 5} \\
\mathbf{m m}\end{array}$ & Permeate flow rate , L/min \\
\hline 0.5 & $32 \%$ & $37 \%$ & 1 \\
\hline 3 & $34 \%$ & $42 \%$ & 1 \\
\hline 3 & $35 \%$ & $44 \%$ & 2 \\
\hline
\end{tabular}

Table 1: Summarized results of \% enhancement of mass flux.

enhancement in mass flux is calculated at average temperature. The first line in Table 1 shows that at a gap height of $3 \mathrm{~mm}$, the contribution of the corrugated feed channel is $32 \%$ enhancement in mass flux and when the gap height is reduced to 1.5 the effect reached to $37 \%$. This indicates the corrugated feed channel effect is dominant rather than decreasing the feed channel height. At a gap height of $1.5 \mathrm{~mm}$, when the feed flow rate increases from 0.5 up to $31 / \mathrm{min}$ ( 6 times), the percentage enhancement of mass flux increases from $37 \%$ to $42 \%$. This indicated that the contribution of the feed flow rate increase (up 6 times) has only $5 \%$ while the corrugated feed channel contribution is calculated as $37 \%$. Table 1 shows also, that at a gap height of $1.5 \mathrm{~mm}$, the increase of permeate flow from 1 up to $2 \mathrm{l} / \mathrm{min}$, the mass flux enhancement varies from $42 \%$ to reach $44 \%$. This results show that the contribution of doubling the permeate flow rate is only represented by $2 \%$ while the contribution of the corrugated channel is $42 \%$ which reflects the dominated effect of the corrugated feed channel design.

\section{Effect of the feed corrugated channel on the thermal energy efficiency}

Figure 8 shows the effect of the feed temperatures on the thermal energy efficiency of the original and corrugated modules. The feed flow rate is controlled at $0.5 \mathrm{~L} / \mathrm{min}$, while the permeate flow rate is fixed at $1 \mathrm{~L} / \mathrm{min}$. The hot feed concentration is measured as $0.45 \mathrm{~g} / \mathrm{L}$ is used. The feed temperature varies from 42 to $68^{\circ} \mathrm{C}$ for feed side while the permeate inlet temperature is kept constant at $20^{\circ} \mathrm{C}$. Different gap height of $1.5 \mathrm{~mm}$ and $3 \mathrm{~mm}$ are carried out.

As shown in Figure 8, the energy efficiency increases as the feed temperature increases. The energy efficiency of the corrugated module is higher than the original module. At a gap height of $3 \mathrm{~mm}$, the experimental results showed the energy efficiency of the corrugated efficiency is $23 \%$ higher than the original module. This is because of created eddies along the corrugated surface which minimize the thermal boundary layer. Decreasing the gap height to $1.5 \mathrm{~mm}$, the energy efficiency of the corrugated module is $26 \%$ higher than the original module.

Figure 9 shows comparison between the energy efficiency of the original and that of the corrugated modules at constant feed flow rate of $3 \mathrm{~L} / \mathrm{min}$ and permeate flow rate of $1 \mathrm{l} / \mathrm{min}$. At the gape height of $3 \mathrm{~mm}$, the average energy efficiency of the corrugated module is $28 \%$ higher than that of the original module. However, at the gap height of $1.5 \mathrm{~mm}$, the energy efficiency is $30 \%$ higher than that of the original module.

Conducting experiment at various permeate flow rates, and the permeate temperature varies from 20 to $31^{\circ} \mathrm{C}$ while, the temperature of the feed is fixed constant at $68^{\circ} \mathrm{C}$ and feed flow rate of $3 \mathrm{~L} / \mathrm{min}$, show that increasing the permeate temperature decreases the energy efficiency as shown in Figures 10 and 11. This is due to decreasing the driving force of vapor pressure difference.

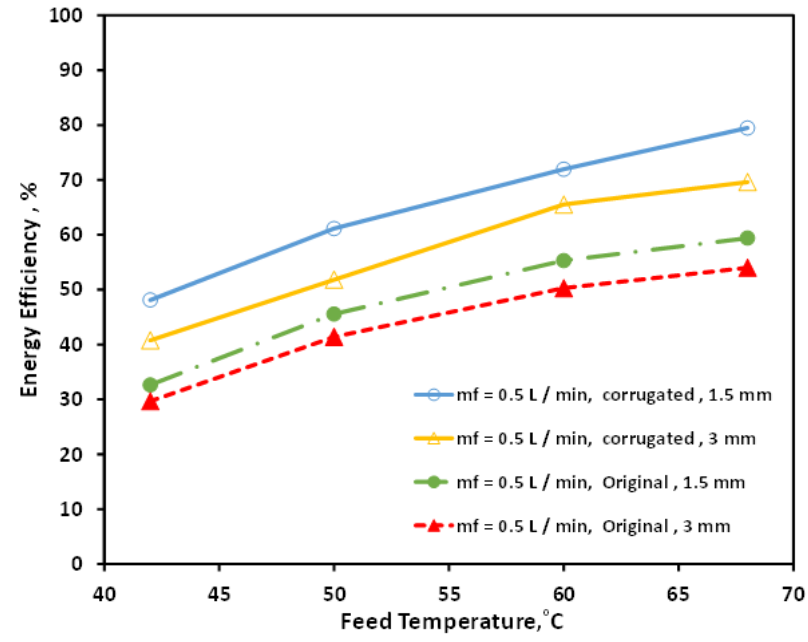

Figure 8: Energy efficiency with different feed temperature and different gaps (Feed flow rate $=0.5 \mathrm{l} / \mathrm{m}$, permeate flow rate $=1 \mathrm{I} / \mathrm{min}$, permeate temperature $=20^{\circ} 0 \mathrm{C}$, Feed TDS $=0.45 \mathrm{~g} / \mathrm{L}$ ). 


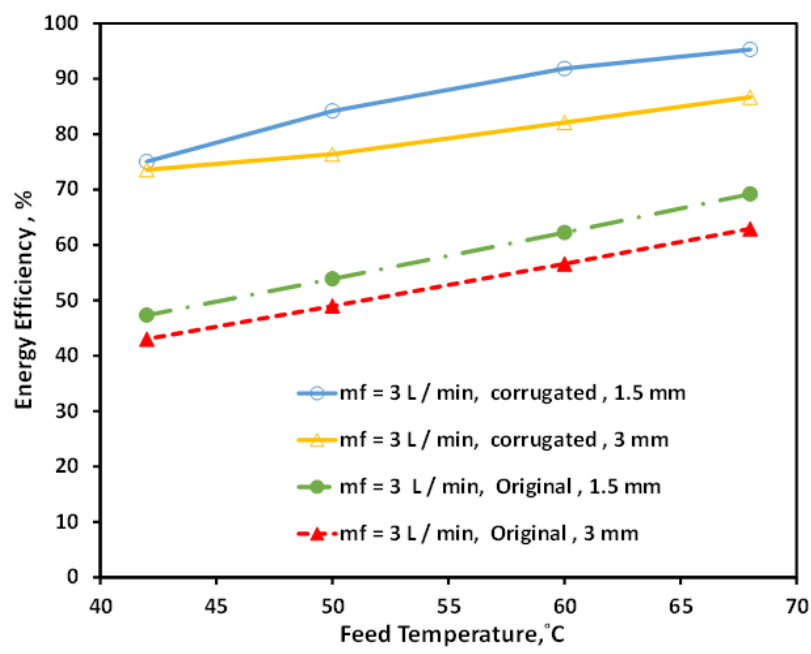

Figure 9: Energy efficiency with different feed temperature and different gaps (Feed flow rate $=3 \mathrm{l} / \mathrm{m}$, permeate flow rate $=1 \mathrm{I} / \mathrm{min}$, permeate temperature $=$ $20^{\circ} \mathrm{C}$, Feed TDS $=0.45 \mathrm{~g} / \mathrm{L}$ )

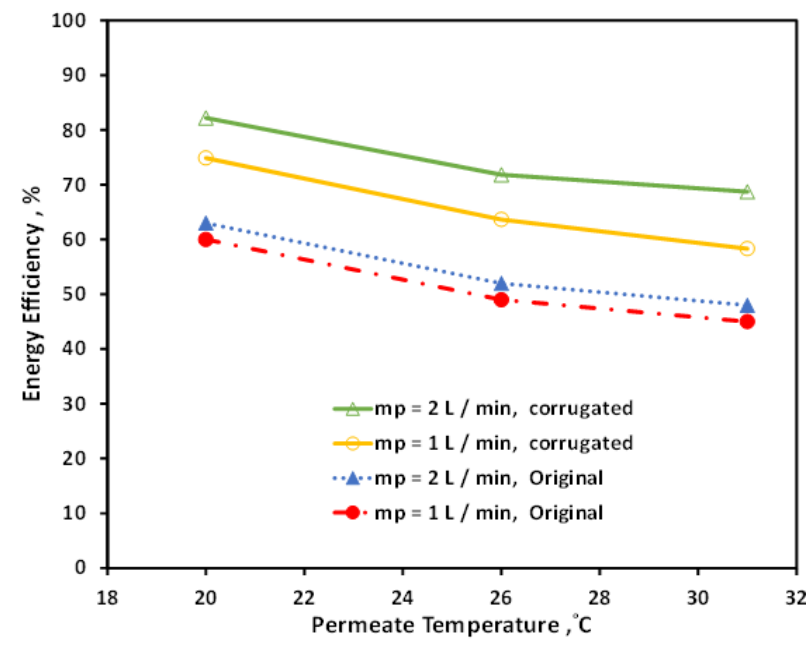

Figure 10: Effect of energy efficiency with different permeate flow rate and temperature at gap $=3 \mathrm{~mm}\left(\mathrm{mf}=3 \mathrm{~L} / \mathrm{min}, \mathrm{tp}=20^{\circ} \mathrm{C}, \mathrm{TDS}=0.45 \mathrm{~g} / \mathrm{L}\right)$.

Figure 10 shows that the corrugated module enables to enhance the energy efficiency of DCMD by $31 \%$ higher than that of the original module. This is due to enhancing in the mass transfer as a result of created turbulence flow in the feed channel.

Figure 11 shows the permeate temperature varies from 20 to $31^{\circ} \mathrm{C}$ while the feed flow rate and temperature are fixed at $3 \mathrm{~L} / \mathrm{min}$ and $68^{\circ} \mathrm{C}$ respectively. The energy efficiency increases as the permeate flow increases due to enhancement of the mass transfer. The energy efficiency enhanced as the gap height decrease; this is due to the increase of the flow velocity which decreases the thermal boundary layer. At a channel height of $1.5 \mathrm{~mm}$ and permeate flow at $2 \mathrm{l} / \mathrm{min}$, the energy efficiency of the corrugated module is $33 \%$ higher than that of the original module.

Table 2 summarized the experimental results of thermal efficiency as a result of varying the feed channel (gap) height, the feed flow rate and the permeate flow rate. The percentage enhancement in thermal efficiency is calculated at average temperature. At a gap height of $3 \mathrm{~mm}$, the contribution of the corrugated feed channel is $23 \%$ enhancement in mass flux. When the gap height is reduced to $1.5 \mathrm{~mm}$ the combined effect reached to $26 \%$. This indicates that the corrugated feed channel effect is dominant rather than decreasing the feed channel height. At a gap height of $1.5 \mathrm{~mm}$, Table 2 also shows that the increase of the feed flow rate from 0.5 up to $3 \mathrm{l} / \mathrm{min}$ ( 6 times), the percentage enhancement of thermal efficiency increases from $26 \%$ to $30 \%$. This indicated that increases the feed flow rate up 6 times has only 4\% while the $26 \%$ represents the corrugated feed channel contribution. At the gap height of $1.5 \mathrm{~mm}$, the increase of permeate flow from 1 up to $2 \mathrm{l} / \mathrm{min}$, the thermal efficiency enhancement varies from 30\% to reach 33\% which reflects the dominated effect of the corrugated feed channel. The different between the middle case (second row in Tables 1 and 2), the permeate flow rate is $1, \mathrm{~L} / \mathrm{min}$ while the last case (third row in Tables 1 and 2 ), the permeate flow rate is $2, L / m i n$ in order to investigate the effect of the permeate flow rate on the water flux and thermal efficiency while feed flow rate is fixed at $3 \mathrm{~L} / \mathrm{min}$. the results showed the contribution of increasing the permeate flow rate is considerably small as shown in Tables 1 and 2 .

\section{Effect of feed concentration (TDS) on the water flux}

The feed concentration plays a significant role in the energy efficiency of the system. The feed concentration directly affects the viscosity and activity of fluid. It directly affects the flow and vapor pressure of the solution and increases temperature polarization $[3,7]$. General rule of thumb, increasing concentration, leads to a decrease in the water flux due to decrease in the vapor pressure difference. This can also be true for the energy efficiency as a result of decreasing the flux; consequently, the energy efficiency will decrease.

Figure 12 shows that as the feed concentration increases, the mass flux decreases as well. Different feed temperatures are also implemented along with different concentration are used to conclude the effect of

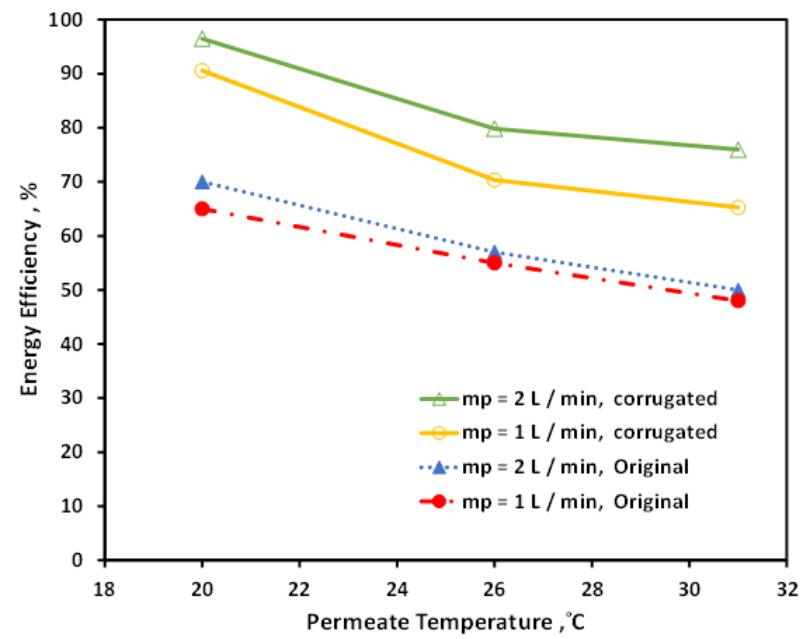

Figure 11: Effect of energy efficiency with different permeate flow rate and temperature at gap $=1.5 \mathrm{~mm}\left(\mathrm{mf}=3 \mathrm{~L} / \mathrm{min}, \mathrm{tp}=20^{\circ} \mathrm{C}, \mathrm{TDS}=0.45 \mathrm{~g} / \mathrm{L}\right)$.

\begin{tabular}{|c|c|c|c|}
\hline $\begin{array}{c}\text { Feed flow rate, } \\
\text { L/min }\end{array}$ & Gap height, 3 $\mathbf{~ m m}$ & Gap height, $\mathbf{1 . 5} \mathbf{~ m m}$ & Permeate , L/min \\
\hline 0.5 & $23 \%$ & $26 \%$ & 1 \\
\hline 3 & $28 \%$ & $30 \%$ & 1 \\
\hline 3 & $31 \%$ & $33 \%$ & 2 \\
\hline
\end{tabular}

Table 2: Summarized results of $\%$ enhancement of thermal efficiency. 


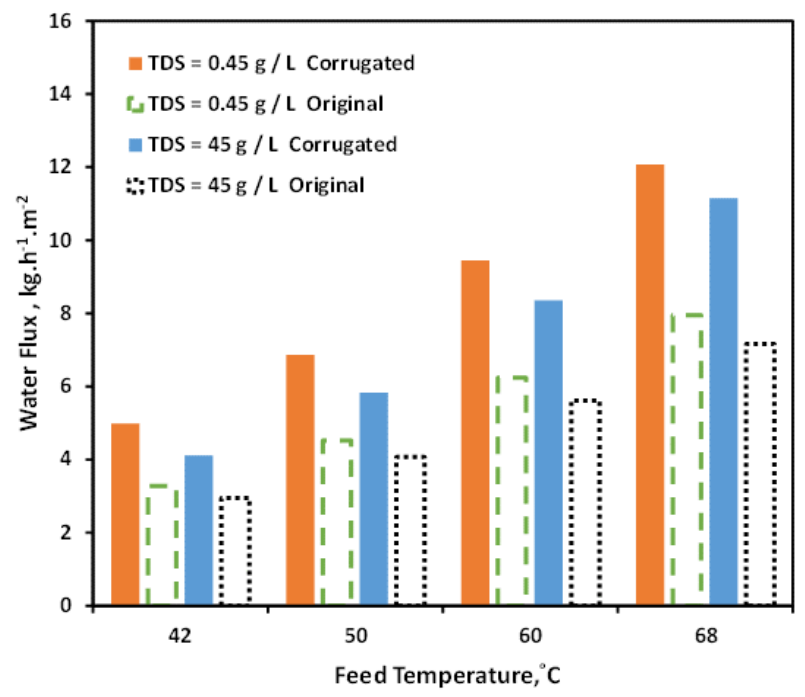

Figure 12: Comparison between the original and corrugated modules for various feed concentration and temperature $\left(\mathrm{Gap}=3 \mathrm{~mm}, \mathrm{tp}=20^{\circ} \mathrm{C}, \mathrm{mp}=\right.$ $1 \mathrm{~L} / \mathrm{min}, \mathrm{mf}=3 \mathrm{~L} / \mathrm{min})$.

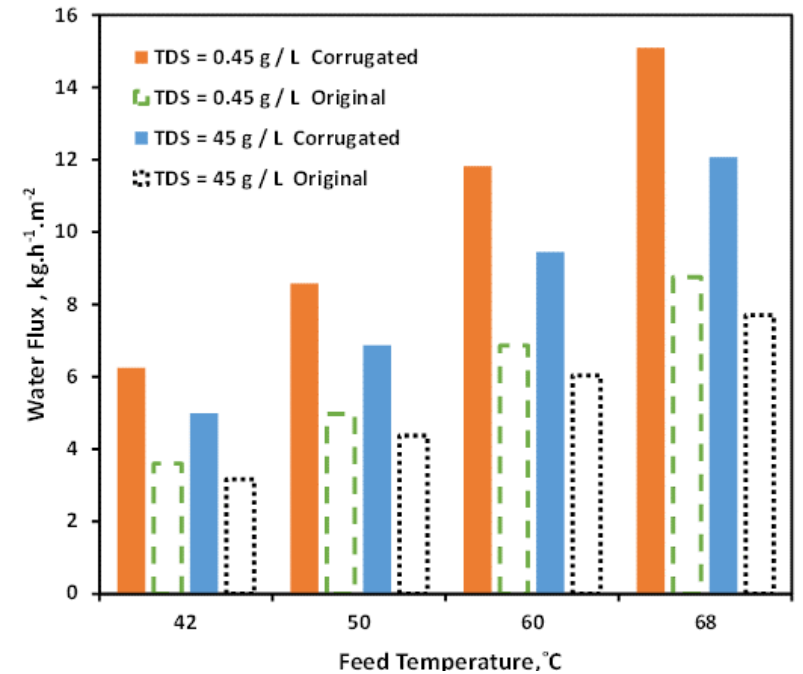

Figure 13: Comparison between the original and corrugated modules of water flux for various feed concentration and temperature $(\mathrm{Gap}=1.5 \mathrm{~mm}$, tp $\left.=20^{\circ} \mathrm{C}, \mathrm{m}_{\mathrm{p}}=1 \mathrm{~L} / \mathrm{min}, \mathrm{m}_{\mathrm{f}}=3 \mathrm{~L} / \mathrm{min}\right)$.

concentration on water flux. The permeate temperature is fixed at $20^{\circ} \mathrm{C}$, while the feed flow rate is $3 \mathrm{l} / \mathrm{min}$. It is seen from Figure 12, that the average water flux of the corrugated module of DCMD is $34 \%$ higher than that of the origin module (at feed concentration of $45 \mathrm{~g} / \mathrm{L}$ ).

Figure 13 shows the effect of feed concentration on water flux at the gap $1.5 \mathrm{~mm}$. The experimental comparison shows that at the feed concentration $45 \mathrm{~g} / \mathrm{l}$ and gap of $1.5 \mathrm{~mm}$, the average water flux of the feed channel corrugated DCMD module is $44 \%$ higher than that of the original module.

\section{Conclusions}

New corrugated feed channel is suggested and equipment with flat sheet direct contact membrane distillation in order to enhance the mass flux and thermal energy efficiency. The effect of the feed channel (gap) height, feed flow rate, temperature and feed salinity are experimentally investigated. The experiments showed that the corrugated feed channel has dominant effect of improving of the mass flux and the thermal efficiency rather than gap height and operating conditions. The experimental results showed that at the feed flow rate of $3 \mathrm{l} / \mathrm{min}$ and $68^{\circ} \mathrm{C}$ while the permeate flow rate of $2 \mathrm{l} / \mathrm{min}$ and $20^{\circ} \mathrm{C}$, the contribution of the corrugated feed channel module at $1.5 \mathrm{~mm}$ gaps is summarized as follow:

- The average water flux is $44 \%$ higher than the original module.

- The average thermal energy efficiency is $33 \%$ higher than the original module.

\section{References}

1. Jönsson AS, Roland W, Harrysson AC (1985) Membrane distillation-A theoretical study of evaporation through microporous membranes. Desalination 56: 237-249.

2. El-Bourawi MS, Ding Z, Ma R, Khayet M (2006) A framework for better understanding membrane distillation separation process. J Memb Sci 285: 4-29

3. Khayet, Mohamed, Matsuura T (2011) Membrane distillation: principles and applications. Elsevier

4. Alklaibi AM, Lior $N(2006)$ Heat and mass transfer resistance analysis of membrane distillation. J Memb Sci 282: 362-369.

5. Termpiyakul $P$, Jiraratananon $R$, Srisurichan $S$ (2005) Heat and mass transfer characteristics of a direct contact membrane distillation process for desalination. Desalination 177: 133-141.

6. Tzahi YC, Adams VD, Childress AE (2004) Experimental study of desalination using direct contact membrane distillation: a new approach to flux enhancement. J Memb Sci 228: 5-16.

7. Chen, Tsung-Ching, Ho CD (2010) Immediate assisted solar direct contact membrane distillation in saline water desalination. J Memb Sci 358: 122-130.

8. Kharraz JA, Bilad MR, Arafat HA (2015) Flux stabilization in membrane distillation desalination of seawater and brine using corrugated PVDF membranes. J Memb Sci 495: 404-424.

9. Tun CM, Fane AG, Matheickal JT, Sheikholeslami R (2005) Membrane distillation crystallization of concentrated salts-flux and crystal formation. J Memb Sci 257: 144-155.

10. Qtaishat M, Khayet M, Matsuura T (2009) Novel porous composite hydrophobic/ hydrophilic polysulfone membranes for desalination by direct contact membrane distillation. J Memb Sci 341: 139-148.

11. Sudoh M, Takuwa K, lizuka H, Nagamatsuya K (1997) Effects of thermal and concentration boundary layers on vapor permeation in membrane distillation of aqueous lithium bromide solution. J Memb Sci 131: 1-7.

12. Tsung-Ching C, Ho CD (2010) Immediate assisted solar direct contact membrane distillation in saline water desalination. J Memb Sci 358: 122-130.

13. Zhang J, Dow N, Duke M, Ostarcevic E, Gray S (2010) Identification of material and physical features of membrane distillation membranes for high performance desalination. J Memb Sci 349: 295-303.

14. Martinez L, Rodríguez-Maroto (2007) Effects of membrane and module design improvements on flux in direct contact membrane distillation. Desalination 205 97-103.

15. Winter D, Koschikowski J, Düver D, Hertel P, Beuscher U (2013) Evaluation of $\mathrm{MD}$ process performance: effect of backing structures and membrane properties under different operating conditions. Desalination 323: 120-133.

16. Phattaranawik J, Jiraratananon R, Fane AG, Halim C (2001) Mass flux enhancement using spacer filled channels in direct contact membrane distillation. J Memb Sci 187: 193-201. 